\title{
CORAZONAR \\ DESDE LAS SABIDURÍAS \\ INSURGENTES EL \\ SENTIDO DE LAS \\ EPISTEMOLOGÍAS \\ DOMINANTES, PARA \\ CONSTRUIR SENTIDOS \\ OTROS DE LA \\ EXISTENCIA
}

Patricio Guerrero Arias

\section{Corazonamientos iniciales}

La celebración rimbombante del Bicentenario en nuestro continente, ha invisibilizado una realidad sobre la cual muy poco se ha discutido, que si bien, los procesos de independencia enfrentaron el colonialismo,

\footnotetext{
* Músico, cantautor, poeta y antropólogo. Docente en las Carreras de Antropología Aplicada y Comunicación Social de la Universidad Politécnica Salesiana.
} 
posibilitaron la continuidad de la colonialidad, de una matriz colonial-imperial de poder que opera para el control absoluto de la vida, de lo político, de lo económico, de la naturaleza, de la espiritualidad, de la cultura; pero sobre todo, para el control de los saberes, de las subjetividades, de los imaginarios y los cuerpos, así como de las afectividades.

La colonialidad del saber no sólo impuso como hegemónico un epistemocentrismo que ha sido instrumental al poder, sino que negó la existencia de otras formas de conocer, de otras sabidurías desde las cuales la humanidad ha tejido la vida. Una de las formas más perversas de la colonialidad del poder y del ser, ha sido la negación de la afectividad en el conocimiento, se fragmenta en nombre de la razón cartesiana occidental hegemónica la dimensión de lo humano, mientras que para las sabidurías shamánicas, los seres humanos no somos sino, "estrellas con corazón y con conciencia".

Lo que proponemos en el presente artículo, es que 'Corazonar'constituye una respuesta política insurgente frente a la colonialidad del poder, del saber y del ser, pues desplaza la hegemonía de la razón y muestra que nuestra humanidad se constituye entre la interrelación entre afectividad y razón y que tiene como horizonte la existencia, de ahí que Corazonar, desde las sabidurías insurgentes el sentido de las epistemologías dominantes, puede contribuir a la construcción no sólo de una distinta propuesta académica y epistémica, sino sobre todo, de sentidos otros de la existencia.

\section{Colonialismo y colonialidad}

Al siguiente día del 10 de agosto de 1809, en el que supuestamente habíamos logrado la 'independencia' en Quito, apareció pintado en el muro de la casa de 
gobierno, una profética frase que anunciaba la realidad futura de los pueblos 'independizados' de nuestro continente: "Fin del despotismo, y primero de lo mismo".

Esto evidenciaba, que si bien las luchas contra el colonialismo español, lograron trastocar las formas administrativas del orden colonial, no lograron transformar las relaciones de poder sobre las que dicho orden se sustentaba; por el contrario, los procesos de independencia, si bien enfrentaron el 'colonialismo', posibilitaron la continuidad de la 'colonialidad' de una matriz colonial-imperial de poder que trasladó la hegemonía a las elites criollas locales, pero mantuvo la misma situación de dominación y subalternización de los pueblos indios y negros, a quienes no sólo se les arrebató recursos materiales y simbólicos, sino su propia condición de humanidad y cuya realidad de discriminación y subalternización se mantiene hasta estos días.

De ahí la necesidad de hacer una lectura crítica de lo que implica la celebración del Bicentenario, y más todavía en una etapa marcada por la dominación global y la colonialidad del mercado. ¿Tenemos alguna independencia que celebrar? ¿Se mantiene vigente la colonialidad en todos los ámbitos de la vida?

Es por ello que resulta, no sólo conceptual sino políticamente necesario, hacer una clara distinción entre lo que es el colonialismo y la colonialidad. El colonialismo hace referencia a un momento histórico marcado por la dominación, la administración política, económica, cultural, etcétera, de determinadas metrópolis sobre sus colonias, pero que no adquirieron un carácter uni-versal ${ }^{1}$, y que, supuestamente, terminó con la independencia. Mientras que la colonialidad se refiere a un proceso de dominación que no ha concluido, que se inicia con la conquista y permanece vigente. Es una realidad de dominación y dependencia a escala planetaria y uni-versal, que 
sobrepasó el periodo colonial, se mantuvo en el periodo de surgimiento de los Estados nacionales y continúa operando en la actualidad con el capitalismo global-imperial.

Esto plantea también la necesidad política de diferenciar que, así como el colonialismo hizo necesarios procesos de lucha por la descolonización; la vigencia de la colonialidad hoy nos plantea la necesidad de la de-colonialidad (Walsh, et. al., 2006), que busca transformar no sólo las dimensiones estructurales, materiales del poder y de sus instituciones y aparatos de dominación como buscaba la descolonización; sino que la decolonialidad busca, sobre todo, enfrentar la colonialidad del saber y del ser y transformar radicalmente las subjetividades, los imaginarios, las sensibilidades, por eso hace de la existencia su horizonte, la recuperación de la humanidad y de la dignidad negadas por la colonialidad. La descolonialidad se plantea la lucha por un horizonte otro de civilización y de existencia.

\section{La matriz colonial-imperial de poder}

El descubrimiento de América hace posible la planetarización de la dominación, pues la colonialidad y la modernidad que emergen de dicho proceso, y que se sustentan en la implementación de una matriz colonialimperial de poder, le posibilita a occidente, instaurar por primera vez en la historia de la humanidad, un nuevo patrón global, uni-versal de poder, para el control absoluto de la vida, de lo político, de lo económico, de lo social, de la cultura, de la naturaleza, de los saberes, de las subjetividades, de los imaginarios, de los cuerpos y de las afectividades. Matriz colonial-imperial de poder que se sustenta en la violencia y el despojo, y que ha estado presente como un continum histórico desde los iniciales proyectos colonialistas de Colón hasta los actuales proyectos 
imperialistas globales de Obama. De ahí que la globalización actual, no sea sino una nueva careta del viejo rostro de la dominación.

Como consecuencia de la colonialidad y de la modernidad que son mutuamente constitutivas y constituyentes, Europa se autoconstituye como centro y construye a las otras culturas y pueblos como periferias, a las que mirará desde entonces como primitivas e incivilizadas; se erige como horizonte 'uni-versal' civilizatorio, como ideal, como norma, como espejo, del cual los otros pueblos serán siempre su pálido reflejo; autoasume el monopolio de la enunciación y se erige como voz, mientras que las periferias serán meros ecos condenados a repetir sus discursos de verdad. Se legitima así un orden monocultural hegemónico, totalitario, que niega la riqueza de la diversidad y la diferencia, la existencia de otras formas de mirar el mundo y de tejer la vida.

Dos construcciones ideológico político sociales se vuelven claves para el ejercicio de la colonialidad: el 'uni-versalismo' y el racismo. Por un lado, el 'uni-versalismo' naturaliza y legitima la superioridad de los dominadores; en su nombre, Europa legitima el derecho que se atribuye a sí misma, de ejercer la dominación y justificar su tarea civilizatoria sobre los 'otros' pueblos, sociedades y culturas, a las que mira como salvajes, primitivas, subdesarrolladas o premodernas, para llevarnos e imponernos desde entonces, su civilización, su desarrollo, su modernidad.

Mientras que, por otro lado, el racismo naturaliza y biologiza la inferioridad de los dominados; la raza y el racismo se vuelven los ejes de las configuraciones geopolíticas que determinan la producción y reproducción de la diferenciación colonial, que imponen la clasificación, jerarquización y subalternización de seres humanos, sociedades, conocimientos y culturas. 
La diferenciación colonial inaugura una dicotomía que estará desde entonces vigente en toda nuestra historia, por la cual ellos se asumen como civilizados, desarrollados y modernos; mientras que a nosotros nos mirarán, desde entonces, como primitivos, subdesarrollados y premodernos; pues mientras ellos están en la historia, nosotros en la pre-historia, ellos tienen cultura, nosotros sólo folklor; ellos ciencia, nosotros mitos; ellos arte, nosotros artesanía; ellos literatura, nosotros tradición oral; ellos religión, nosotros hechicería; ellos tienen medicina, nosotros magia.

La matriz colonial-imperial de poder impone la colonialidad como forma de dominación, para el control absoluto de la vida, la misma que opera en tres niveles claves: colonialidad del poder, del saber y del ser.

\section{La colonialidad del poder}

Se refiere a los aspectos sistémicos, estructurales de la dominación. A las dimensiones constitutivas y constituyentes, a las instituciones y sus aparatos de control, que posibilitan la naturalización y uni-versalización de los órdenes dominantes, a fin de que difícilmente puedan ser cuestionados.

La colonialidad del poder naturaliza y universaliza la dominación en varios ámbitos de la vida:

- En lo político: la democracia y el régimen liberal aparecen como los únicos modelos uni-versales de construcción de lo político. Se subalterniza y se consideran atrasadas, otras formas de constitución y organización política de las sociedades. La democracia que se reduce a ser meramente delegativa, ha sido incapaz de transformar las relaciones de poder, de disminuir los privilegios de las elites, y no 
ha enfrentado las grandes asimetrías, desigualdades e injusticias sociales producidas por la colonialidad; sin embargo, opera como el más eficiente mito, que naturaliza un orden que se vuelve incuestionable, lo que le permite al poder hegemónico su continua y permanente reestructuración, legitimación y ejercicio.

- En lo económico: el capitalismo se muestra como el único modelo planetario de regulación económica; como el camino a la felicidad y al desarrollo, el mismo que se sustenta en una visión evolucionista y unilineal de progreso; y que ha hecho de la universalización del desarrollo unilineal, el más efectivo discurso civilizatorio, que se impone sobre otras racionalidades y sabidurías de pueblos que no se sustentan en la acumulación del capital, sino en formas de solidaridad, reciprocidad y redistribución.

- La colonialidad de la naturaleza: es una consecuencia de la visión capitalista, puesto que Occidente se erige como una civilización que prioriza el capital sobre la vida. Esta visión instrumental, falocéntrica y desacralizada de occidente, rompe los lazos sagrados y espirituales con la vida, lo que ha provocado que la naturaleza sea transformada en mercancía, en simple recurso, en objeto para generar plusvalía y acumular ganancias. La actual crisis ambiental que estamos enfrentando, es el más claro reflejo de la actual crisis civilizatoria, consecuencia de la lógica ecocida ${ }^{2}$ de occidente; que no es provocada por los pueblos subdesarrollados o premodernos, sino por las políticas de muerte neoliberales que buscan imponer su perspectiva de modernidad y desarrollo y que están matando la vida. 
- En lo religioso: el Cristianismo se instituye como religión verdadera y uni-versal. Se subalterniza así otras religiosidades y espiritualidades a las que se considera herejías, hechicería, para justificar su persecución y exterminio. La colonialidad provoca la desacralización de la vida, que lleva a la ruptura con la fuerza de la espiritualidad y lo sagrado, para convertir la naturaleza, el mundo y la vida en objetos a ser explotados.

- En lo lingüístico: las lenguas gringo-europeas se erigen como las únicas lenguas de conocimiento y para la producción de los discursos de verdad de la ciencia y la técnica. Las otras lenguas son exotizadas, se las ve como simples dialectos, e incapaces de construir conocimiento, pues este sólo se produce en las lenguas hegemónicas. Una expresión de la colonialidad lingüística, es que las propias universidades priorizan el inglés y las lenguas europeas más que a las lenguas nativas.

- En lo cultural: Occidente y Europa se establecen como la expresión suprema de la civilización humana y, por tanto, como centro uni-versal civilizatorio; los otros pueblos y culturas como periferias atrasadas, condenadas a la dependencia, a seguir inevitablemente el horizonte monocultural civilizatorio que se nos impone. Una consecuencia de esto es la internalización de una razón colonial que se recrea continuamente, por la que se nos enseñó a bailar sobre nuestros muertos y a celebrar las derrotas, pues aún seguimos festejando las fechas de la conquista y a los conquistadores como en la celebración del 6 de Diciembre, día de la fundación de Quito; donde se impone el dominio de lo ajeno sobre lo propio, la fetichización de lo extranjero, lo que va minando la fortaleza de nuestras raí- 
ces de identidad, para obligarnos a entrar en la globalización del mercado sin rostro propio.

\section{La colonialidad del saber}

Con la conquista se construye un patrón de conocimiento profundamente articulado al ejercicio del poder, sustentado en una razón colonial que ha tenido las características de un espejo, que nos construyó imágenes deformantes de la realidad, y que nos ha condenado a ser un reflejo de otros procesos, de otras territorialidades y experiencias históricas; que nos usurpó la palabra, para que seamos un simple eco de otras voces que autoasumieron la hegemonía de la enunciación, por ello heredamos un saber ventrílocuo, que no habla por sí mismo, ni con sus propias palabras, ni desde sus propias territorialidades, realidades y lugares; sino que nos ha condenado a ser simple eco, a una monofonía, que sólo escucha y repite el discurso de verdad de la ciencia occidental, por ello hemos estado condenados a copiar siempre lo extraño y sujetados hasta hoy, al orden epistémico euro-gringo-céntrico dominante. Colonialidad del saber que nos ha impedido visibilizar a actores, saberes, conocimientos, sabidurías, prácticas de existencia, que desde el mismo momento en que se coloniza la vida, han estado en procesos de lucha de re-existencia (Albán, 2006) y de insurgencia material y simbólica, en perspectiva de la construcción de horizontes distintos, 'otros' de existencia.

La colonialidad del saber impone una colonialidad epistémica sustentada en la hegemonía y universalización de la razón y el imperio de la ciencia y la técnica como únicos discursos de verdad para poder hablar sobre el mundo y la vida. Se constituye como hegemónica la epistemología de la ciencia moderna, y así se silencian e invisibilizan otras culturas y sabidurías que están fuera de 
la epistemología dominante, y se considera que son incapaces de sentir, pensar, decir y hacer por sí mismas, y peor de poder construir conocimientos, sino apenas saberes pre-científicos que son vistos como curiosidades exóticas a ser estudiadas. Y a los actores subalternizados se los ve como simples objetos de conocimientos, como informantes, y no como sujetos con capacidad de producir conocimientos y desde entonces se construye una perversa dicotomía entre trabajo manual e intelectual.

Pero una de las consecuencias más graves de la colonialidad del saber, es la negación de la afectividad en el conocimiento, la ausencia de la ternura en la academia.

\section{La colonialidad del ser}

La colonialidad ya no sólo opera en lo estructural, desde la exterioridad y a través de sus instituciones y sus aparatos represivos, sino que se instaura en lo más profundo de nuestras subjetividades, de los imaginarios, la sexualidad y los cuerpos, para hacernos cómplices conscientes o inconscientes de la dominación. Para la imposición de la colonialiad del poder y del saber se tienen instituciones y aparatos represores como el Estado, los tribunales, los bancos, las ONG, la Iglesia, las escuelas, las universidades, el ejército, la policía, los medios de desinformación, etcétera, que operan desde la externalidad; pero para el ejercicio de la colonialidad del ser, el poder instala el represor dentro de nosotros mismos, manipula desde lo más intimo de nuestras subjetividades y cuerpos, y ahí radica la eficacia que tiene la colonialidad del ser, pues así se construyen subjetividades alienadas, sujetos sujetados, se impone un ethos útil a la dominación, para la imposición de la razón colonial en las subjetividades, que hace más viable la colonialidad del poder y del saber. 
Un ejemplo claro de la colonialidad del ser, es la noción de pecado y culpa, pilares de la religión judeo-cristina de occidente, que nos ha conducido a la negación del cuerpo, del placer, a la vergüenza de ser felices, a la deserotización del mundo y la vida, al deterioro de la autoestima, al fomento de la mediocridad necesaria para reproducir subjetividades útiles al sistema; y que provoca también, la negación de la diferencia, la desvalorización de la memoria colectiva, la construcción de subjetividades e identidades negativas. Pero quizás una de las formas más perversas de la colonialidad del ser, es la colonialidad de la afectividad, la colonialidad del corazón.

\section{La colonialidad de la alteridad}

Esta es una dimensión sobre la que no se discute cuando se habla de la colonialidad. La colonialidad de la alteridad se expresa en la radical ausencia del otro, este no es visibilizado, no existe, se lo despoja de humanidad y dignidad. La colonialidad construye dicotomías y polaridades, que fracturan la alteridad, puesto que todo lo que está fuera del centro hegemónico, es su 'otro'; así, toda sociedad, pensamiento, conocimiento de los 'otros', serán vistos como obstáculo, como carencia, como inferioridad, como amenaza, como enemigo.

De esta forma se construyeron dicotomías excluyentes que están plenamente vigentes, por las que se ve a la naturaleza como 'lo otro' y opuesto de la cultura; al cuerpo del alma; a la afectividad y las emociones de la razón; a lo femenino de lo masculino; a lo privado de lo público, a lo manual de lo intelectual.

La colonialidad del ser y la alteridad implica el sujetamiento de los sujetos, por eso se nos aleja de nosotros mismos y de los otros. El poder fractura la alteridad, pues si somos con los otros, hay que evitar ese encuentro. 
Se construye un imaginario de la alteridad como radical exterioridad de la 'otredad' frente a la 'mismidad'. Lo otro es lo extraño, lo lejano, lo peligroso, lo que nos amenaza, lo que debe ser controlado y dominado. Pero como enseña la sabiduría Nahual: Yo soy tú; tú eres yo; y juntos somos Dios. De ahí que la alteridad no es sino el encuentro entre la mismidad y la otredad, puesto que inevitablemente el otro habita en nosotros, y nosotros habitamos inexorablemente en el otro, no podemos ser sin los otros. Es en el encuentro afectivo, que la mismidad y la otredad se vuelve un nosotros, así podemos pensar y luchar por horizontes compartidos de existencia.

Otra consecuencia de la colonialidad de la alteridad es la visión antropocéntrica de la alteridad occidental, que legitima el dominio masculino sobre la naturaleza, desde el poder de la razón, la ciencia y la técnica, eje del modelo civilizatorio ecocida occidental, que prioriza el capital sobre la vida y que está poniendo en riesgo, las posibilidades de existencia de todo el planeta. La colonialidad fractura una 'alteridad cósmica' como la que han sabido construir las sabidurías de los pueblos subalternizados.

La de-colonización de la alteridad implica por tanto, la radical insurgencia del otro, de la alteridad; volver al otro, hacer visible su presencia, y la de sus sabidurías, de sus horizontes de existencia y empezar a dialogar y a aprender de ellas. Es urgente una 'alteridad cósmica, biocéntrica', que ponga como eje la vida sobre el capital, una ética otra de la alteridad, una ética del amor, que mire a la naturaleza como ese otro con el que estamos hermanados en el milagro de la vida, pues frente a la actual crisis que enfrenta el planeta como expresión de la razón ecocida de occidente, y que está poniendo en riesgo el orden cósmico, si queremos tener perspectivas presentes y futuras para la existencia, necesitamos hacer un urgente pacto de ter- 
nura con la vida, desde la sabiduría del corazón, de ahí que el Corazonar, sea una respuesta insurgente para la decolonización de la vida.

\section{Corazonar las epistemologías dominantes como acto de insurgencia de-colonial}

Si bien desde perspectivas de-colonizadoras hay un innegable esfuerzo en la academia por hacer visible la matriz colonial-imperial de poder; sin embargo, dichas propuestas no han considerado suficientemente una dimensión de la colonialidad, por la que no se ha interesado la academia, ni el pensamiento crítico de-colonial, la 'colonialidad de la afectividad', y lo que es más, dicha afectividad tiene una pálida presencia en sus reflexiones.

Una de las expresiones más perversas de la colonialidad del poder, del saber y del ser, ha sido erigir la razón como el único 'uni-verso' no sólo de la explicación de la realidad, sino de la propia constitución de la condición de lo humano, de ahí la definición desde occidente 'del hombre como ser racional'; en nombre de la astucia de la razón (Walsh, 2005: 115-120), nos secuestraron el corazón y los afectos para hacer más fácil la dominación de nuestras subjetividades, de nuestros imaginarios, de nuestros deseos y nuestros cuerpos, territorios donde se construye la poética de la libertad y la existencia; la hegemonía de la razón fragmenta la condición de nuestra humanidad, pues desconoce que no sólo somos lo que pensamos y peor que sólo existimos por ello como sostiene el fundamentalismo racionalista cartesiano; sino que fundamentalmente, el sentido de lo humano está en la afectividad, no sólo somos seres racionales, sino que somos también sensibilidades actuantes, o como nos enseña la sabiduría shamánica: "somos estrellas con corazón y con conciencia". 
Y así como se colonizó, dominó, silenció, invisibilizó, los conocimientos, saberes, prácticas y a seres humanos, se colonizó también las sensibilidades, la afectividad, pues constituían la parte que negaba la hegemonía de la razón y de un pensamiento e ideología guerrerista que era necesario para el ejercicio del poder, pues al estar marcado por la ausencia de sensibilidad, lo otro, y los otros, el mundo, la naturaleza, las sociedades, las culturas, los seres humanos y la vida, se vuelven objetos de dominio, cosas, recursos, cifras para obtener plusvalía, por eso se hizo necesario legitimar la hegemonía de la razón, y silenciar la voz del corazón; por tanto no podía haber lugar en el conocimiento racional para la afectividad, para la ternura; por eso se consideró que los sentimientos pertenecían a la esfera de la animalidad, de lo instintivo, y por tanto debían ser negados, marginalizados, reprimidos y conducidos a espacios subterráneos. Sentir era una forma de negar el carácter patriarcal, masculino, dominador, irracional de la razón hegemónica, en consecuencia la afectividad, será excluida de la vida intelectual y de la esfera de lo público.

Los sentimientos, las emociones, las sensibilidades, la ternura, no podían ser parte del mundo académico, no serán consideradas como otras fuentes de conocimiento; sentir, sólo podía darse en aquellos sujetos que estaban en esferas no racionales, como las mujeres, los locos, los poetas, los artistas y los niños, puesto que la razón tiene lugar, pues era y sigue siendo euro-gringocéntrica; tiene color (ibíd), pues la razón es blanca; y tiene género pues es hegemónicamente masculina; por lo tanto, no podían poseerla las mujeres, los niños, menos aún las culturas y sociedades consideradas primitivas, como los negros y los indios, a quienes se les negó la posibilidad de pensar, de sentir, de ser, se les negó su condi- 
ción de humanidad, como la forma más perversa de la colonialidad del ser.

Si un centro hegemónico de la dominación ha sido siempre la razón, se hace necesario empezar a considerar la dimensión política insurgente que han tenido las afectividades en la lucha por los horizontes de existencia de los pueblos sometidos a la colonialidad; y si un rasgo de esa colonialidad del saber presente en la academia es haber quedado presa de la matriz logocéntrica y epistemocéntrica, nos preguntamos si no es entonces imprescindible recuperar la afectividad y empezar a Corazonar las epistemologías hegemónicas, como un acto de insurgencia (de)colonial...

Corazonar es una respuesta insurgente para enfrentar las dicotomías excluyentes y dominadoras construidas por occidente, que separan el sentir del pensar, el corazón de la razón; implica senti-pensar un modo de romper la fragmentación que de la condición humana hizo la colonialidad. En el razonar, la sola palabra connota la ausencia de lo afectivo, la razón es el centro, y en ella la afectividad no aparece ni siquiera en la periferia. Corazonar busca reintegrar la dimensión de totalidad de la condición humana, pues nuestra humanidad descansa tanto en las dimensiones de afectividad, como de razón. En el Corazonar no hay centro, por el contrario, lo que busca es descentrar, desplazar, fracturar el centro hegemónico de la razón; el Corazonar lo que hace es poner primero algo que el poder siempre negó, el corazón, y dar a la razón afectividad; Corazon-ar, de ahí que el corazón no excluye, no invisibiliza la razón, sino que por el contrario, el Co-Razonar le nutre de afectividad, a fin de que decolonice el carácter perverso, conquistador y colonial que históricamente ha tenido. 


\section{Corazonar una sabiduría de los sentidos y las emociones}

Hoy sabemos que existimos, no sólo porque pensamos, sino porque sentimos, porque tenemos capacidad de amar; por ello, hoy se trata de recuperar la sensibilidad, de abrir espacios para Corazonar desde la insurgencia de la ternura, que permitan poner el corazón como principio de lo humano, sin que eso signifique tener que renunciar a la razón, pues de lo que se trata es de dar afectividad a la inteligencia. Desde las sabidurías ancestrales siempre se supo que nuestra humanidad no reside sólo en la razón, sino que el ser humano desde lo más ancestral del tiempo, tejió la vida desde el corazón, desde la afectividad, desde los universos de sentido que hacen posibles las emociones.

La actual consideración por parte de la academia de la importancia que tienen las emociones, las sensibilidades en la construcción del sentido de la existencia, no ha sido el resultado de una sensibilización de las epistemologías, pues éstas, aún siguen manteniendo su sentido disciplinario y continúan siendo instrumentales al poder, por ello continúan vaciadas de afectividad; sino que ha sido resultado de las luchas de insurgencia material y simbólica de los pueblos subalternizados por el poder; lo que les ha permitido dejar de ser objetos de estudios de la academia, para constituirse hoy como sujetos sociales, políticos e históricos que han evidenciando que históricamente el horizonte vital de sus luchas, ha sido siempre la existencia; lucha que ha sido posible fundamentalmente desde el poder de los afectos y las emociones. Asistimos a un tiempo en el cual, las emociones ya no pueden seguir siendo ignoradas, por ello, como dice el Pueblo Kitu Kara: "Este es el tiempo del Corazonar" y no sólo la academia, sino todas las dimensiones de la vida. 
En este momento histórico, cuando la crisis civilizatoria provocada por la voracidad de occidente no posibilita perspectivas para la continuidad de la vida, es cuando las sabidurías insurgentes, las sabidurías del corazón de pueblos a los que se les negó la vida, son más necesarias que nunca, puesto que ellas nos ofrecen horizontes de esperanza para continuar tejiendo una forma distinta de civilización y de existencia.

Si la cultura no es sino una respuesta que hace posible la reafirmación y transformación de la vida, que nos ofrece horizontes de sentido para el vivir, la cuestión de las emociones no pueden seguir siendo ignoradas, puesto que las emociones a las que se les ha visto como la parte más íntima y secreta de los sujetos, que nada tienen que ver con la cultura, no son sino construcciones de sentido que están social, cultural e históricamente situadas, de ahí que es necesario y urgente que la academia se acerque a la comprensión de los cosmos de sentido que habitan las emociones, no sólo como una cuestión epistémica, sino, sobre todo, de vida.

Una comprensión holística del ser humano y de las construcciones de sentido que teje a través de la cultura, no puede ignorar, que el ser humano tiene una condición tanto biológica como cultural, y que las emociones habitan esos territorios, pues, si bien desde la condición biológica, todos estamos dotados de un cosmos emocional, la forma como éstas se expresarán van a ser moldeadas por cada cultura de manera diferente.

No se puede separar esa dimensión biológica y cultural que constituye la humanidad, y en ellas la dimensión emocional, y concretamente del amor cumple un rol constitutivo y constituyente, de ahí que podríamos hablar de que es una biología del amor (Maturana, 2004), la base sobre la que se construye la dimensión de humanidad que une a la diferencia. 
Las emociones no son sólo expresiones naturales de la fisiología o la psicología humanas, sino que son construcciones simbólicas de sentido que se en-carnan en cuerpos e individuos concretos, socialmente construidos, que encuentran en dichas emociones las posibilidades para la construcción de sus imaginarios, discursos y prácticas que les permite sentir, pensar, hablar, actuar, y las interacciones con el mundo y la vida y con los otros.

Es desde la fuerza cultural de las emociones, con ellas y desde ellas, que se tejen los sentidos de la alteridad y la existencia, el encuentro o desencuentro con los otros, con la diversidad y la diferencia; de ahí que las emociones no tienen un sentido uni-versal como ha buscado siempre el pensamiento homogeneizante de occidente, sino que las emociones sólo pueden ser entendidas desde la pluridiversalidad de las culturas.

Una mirada de los sentidos y las emociones, desde perspectivas políticas, debe considerar la dimensión constitutiva y constituyente de la alteridad en la condición humana, puesto que el otro, la otredad, es la base sobre la que es posible la existencia social; hay una necesidad antropológica que es parte de la constitución de la propia condición humana, que no puede construirse sino sólo sobre las huellas que los otros han dejado y dejan sobre nuestros corazones y nuestros cuerpos, es la existencia del otro, el origen de todo sentido del vivir, lo que nos salva de la soledad y la muerte social, por eso el poder impuso siempre, la colonialidad de la alteridad.

El sentido de la existencia, que construye el pluri-multiverso de significados que hace posible nuestro caminar por el mundo y la vida, sólo es posible por la presencia fundante en nuestras vidas de los otros; la vida es una acto supremo de alteridad, puesto que nada somos sin los otros, puesto que el otro habita inexorablemente 
en nosotros y nosotros habitamos inevitablemente en los otros, pero ese habitar sólo es posible desde un universo simbólico de sentido que se asienta en el emocionar, cuyas huellas se inscriben en lo más profundo del corazón y el cuerpo, a tal punto, que tejemos el vivir, en cuerpos, como dijera Artaud $^{3}$, que están habitados por el mundo.

La consideración de los cosmos de sentido de las emociones, involucran también un posicionamiento político, una forma de ir abriendo procesos para la de-colonización del saber y del ser, pues plantea la necesidad de rupturas radicales con miradas positivistas y epistemocéntricas, con metodologías instrumentales que han objetivado a los otros y los han transformado en objetos de estudio e informantes.

Desde el Corazonar, planteamos la necesidad de la construcción de una 'poética de la alteridad' en la cual, los otros y nosotros estamos presentes habitando los territorios de la vida y es la fuerza del emocionar, la que hace posible que nos encontremos como interlocutores que buscan aprender de sus respectivos universos simbólicos de sentido que han tejido en sus experiencias del vivir.

Superar la colonialidad del saber que ha heredado la academia, implica la construcción de una academia comprometida con la vida, la misma que no puede dejar de lado la dimensión cultural y política que juegan las emociones, la afectividad. Las emociones, por lo tanto, forman parte de una mirada distinta, nos preguntamos, ¿será posible llegar a comprender desde la epistemología, los cosmos de sentido de las afectividades que la misma epistemología, negó, invisibilizó, marginalizó, subalternizó?; la epistemología resulta insuficiente para poder comprenderlas, de ahí que sea necesario, no sólo una 'epistemología de los sentidos', sino una sabiduría de los sentidos y las emociones; por ello, hay que empezar a Cora- 
zonar desde las sabidurías insurgentes, el sentido de las epistemologías dominantes, para poder construir sentidos otros de la existencia.

¿Cómo explicar desde las epistemologías, las teorías y las metodologías de una academia que es funcional al poder, que estudia a los seres humanos como cosas, los cosmos de sentido del dolor, de la soledad y de la muerte? ¿Cómo leer las cartografías del terror en zonas de guerra, de desplazamientos forzosos, de sociedades marcadas por el silencio y el silenciamiento, en donde la lógica de la vida es tan impredecible?

Ahí, en escenarios donde se debe tejer la vida enfrentando a la muerte, como una dura realidad cotidiana, los marcos teóricos, metodológicos, las epistemologías poco ayudan, pues siempre, en investigaciones sobre realidades marcadas por el dolor, el terror y la muerte encontraremos 'indecibles' (Castillejo) ${ }^{4}$, que los epistemes no pueden explicar; la objetividad científica y la fría distancia que debemos tener frente a nuestros 'objetos de estudio', que enseñan los manuales de metodología, involucra la negación de nuestra subjetividad, de nuestra sensibilidad, a fin de que nos volvamos cómplices del poder y su violencia; esos indecibles, marcados por el dolor, la violencia y la muerte, de los que siempre ha estado alejada la academia, no podrán ser comprendidos desde la frialdad de los epistemes; sino sólo desde el calor de la sabiduría de los afectos.

Una mirada de-colonial de los cosmos de sentido, de la fuerza cultural de las emociones, nos plantea, retos políticos, teóricos, metodológicos y éticos, para ir construyendo propuestas que permitan de-colonizar los instrumentos epistémicos, metodológicos y las prácticas de una ciencia instrumental al poder.

Desde el Corazonar, lo que buscamos es la construcción de propuestas teóricas, metodológicas y de mira- 
das éticas y políticas que permitan una praxis que rompa con la falsa neutralidad de la ciencia; desde la certeza que la cultura es una respuesta creadora frente a la vida y para hacer crecer y transformar la vida, y que hace de la existencia, el horizonte de su reflexión y de su praxis; por ello es necesario ir construyendo una academia comprometida con la vida.

\section{El Corazonar como respuesta insurgente desde nuestros propios territorios del vivir}

Un acto de de-colonización, ¿no sería empezar a Corazonar las epistemologías hegemónicas y que aún están presentes en nuestras prácticas académicas?, ¿no será una forma de empezar a sentipensar con el corazón o con todo nuestro cuerpo como expresión de otra forma de corpolítica?; ¿no será otra forma de respuesta política desde nuestros propios territorios del vivir; desde la fuerza insurgente de la sabiduría del corazón y las emociones, que a lo largo de la historia le ha permitido a la humanidad, continuar tejiendo la sagrada trama de la vida?

Corazonar puede vérselo, como una expresión de pensamiento fronterizo, de una geopolítica del conocimiento y de la existencia, tejidos desde nuestros propios territorios del vivir, que siente y piensa desde el dolor de la herida colonial; puede evidenciar esfuerzos de sentipensamientos otros, presentes en América Latina, que hacen evidente la existencia de formas otras de construir conocimiento distintas a la razón (Kusch: 1998, t. II), de la construcción de comunidades sentipensantes (Comunida des afrocolombianas del Pacífico). Pero sobre todo porque se evidencia que el sentir desde el cuerpo, la afectividad, el hablar desde la sabiduría del corazón, tiene un carácter político insurgente que ha sido una práctica continua en 
la lucha por la existencia de los pueblos sometidos a la colonialidad; como nos enseña la sabiduría de las mujeres Mayas, las que al concluir sus discursos dicen: esto es lo que está en mi corazón; o como desde la sabiduría Naza se afirma que es en el corazón donde está el poder para la construcción de la memoria, pues recordar, es volver a pensar desde el corazón; o como lo evidencian las prácticas políticas de los pueblos afroamericanos que ven la africanidad como un sentimiento filosófico y poético; y que están transformando con el cuerpo y los sentimientos, los fundamentos de la vida (Zapata Olivella, 1997). En el corazón, nos enseña la sabiduría Aymara, está la posibilidad no sólo de empezar a 'conocer' de manera distinta la vida, sino de empezar a 'cosmoser', es decir de construir un sentipensamiento articulado a la totalidad del cosmos y la existencia; o como desde la palabra sencilla, pero digna y rebelde, de los indios zapatistas de la selva Lacandona que nos enseñan, que es en el poder del corazón, en donde está la fuerza de la dignidad y la rebeldía, para la lucha por otros mundos posibles; o como dice Magdalena Aranda, sabia anciana de Pastaza-Ecuador: "El calor del corazón es el calor del Inti no hay otro calor más fuerte que el corazón humano, que ama, que siente, que vibra: quién ha perdido el calor del corazón, ha perdido ya la vida".

Si la razón definía el ser (Dussel, 1994) y aquello que lo negaba como la afectividad, estaba destinado al no ser; una forma de combatir la colonialidad del ser y de la afectividad y de recuperar la plenitud de la humanidad negada, no será recuperar ese ser, no desde la razón colonial, sino desde donde hemos re-existido e insurgido frente a la colonialidad del poder, del saber y del ser, desde la sabiduría del corazón y la afectividad; de ahí que el pueblo Kitu Kara haga de la afectividad el centro de su propuesta política en su lucha por la existencia, cuando dicen: "Estamos sintiendo, estamos haciendo, estamos 
siendo"; una evidencia de ello es la convocatoria que realizó el pueblo Kitu Kara a unas jornadas para 'Corazonar la vida', que se acaban de realizar desde 23 al 28 de marzo de este año, como expresión de una distinta dimensión espiritual de la lucha política y de la dimensión política de la espiritualidad.

Las luchas por la existencia de los pueblos subalternizados a lo largo de toda su historia, no se las han hecho sólo desde la razón sino, fundamentalmente, desde las sensibilidades y los afectos, desde el corazón; esas luchas, como nos enseña el viejo Antonio ${ }^{5}$, sólo podían hacerse desde lo más profundo del amor; amor a la humanidad, amor a nuestra tierra, amor a nuestros muertos.

En la fuerza de la afectividad, se refleja la poética de la existencia que ha sido, como lo muestra Zapata Olivella, encontrada incluso en el dolor de la explotación, la miseria y la muerte; de ahí que resulta imposible encontrar una explicación teórica, epistémica a esa voluntad irrenunciable de vida que hace que los pueblos subalternizados por el poder, a pesar de las condiciones de miseria, de dominación y muerte, sigan celebrando la vida, cantando desde la miseria, eso sólo es posible hacerlo desde la sabiduría del corazón, ahí está la fuerza que el poder no ha podido fragmentar, y que ha sido la base de los procesos de resistencia, de re-existencia (Albán, 2006) y de insurgencia material y simbólica de todos los pueblos que han sufrido y sufren la colonialidad en sus propios cuerpos y subjetividades.

Ha sido la fuerza insurgente de la ternura, la esperanza, de los sueños, de la alegría, de mujeres, hombres, ancianos, jóvenes y niños, no como recursos retóricos, ni re-teóricos, sino como fuerzas insurgentes insustituibles para transformar todas las dimensiones de la vida, y que han sido tejidas desde sus propios territorios del vivir; las que han permitido que esos pueblos subalterni- 
zados por el poder, a pesar de estar acorralados por la muerte, no sólo que recuperen la palabra y puedan hablar por sí mismos, sino que sobre todo, luchen, bailen, sonrían y canten, que encuentren desde la profundidad de sus dolores, formas para seguir amando, para seguir soñando y creyendo, para burlar la muerte y para continuar tejiendo la sagrada trama de la vida; es allí donde está la fuerza insurgente para enfrentar la fragmentación de la totalidad de la existencia, que en nombre del imperio de la razón ha querido hacer el poder; pero a pesar de ello, como dice Sábato en su obra La Resistencia: "El ser humano sabe hacer de los obstáculos nuevos caminos, porque a la vida le basta el espacio de una grieta para renacer. En esta tarea lo primordial es negarse a asfixiar cuanto de vida podamos alumbrar... El mundo nada puede contra un hombre que canta en la miseria”.

\section{Un horizonte de sentido civilizatorio y de existencia 'otro', más que de epistemología, requiere de sabiduría}

Se hace necesario una radical acción ética y política, para la desestructuración y de-colonización del paradigma de conocimiento occidental hegemónico; para hacer posible que se expresen, con todo su potencial epistémico, ético, estético y político, las sabidurías insurgentes de otros sujetos y subjetividades, otras espacialidades y temporalidades; otras prácticas, saberes y horizontes de existencia. Si bien las posturas de (re)pensamiento crítico (de)colonial reconocen la necesidad de dialogar con lo que han llamado las 'epistemologías otras', el diálogo con esas otras epistemologías, sujetos y culturas, no se da sino parcialmente y en forma muy tímida y se reduce a la invitación de representantes de dichas culturas, generalmente 
intelectuales orgánicos formados en el manejo del instrumental epistemológico occidental, lo que implica que son las epistemologías euro-gringo-céntricas las que tienen mayor peso en la actual construcción del conocimiento académico.

A pesar del innegable esfuerzo que se realiza por la descolonización del saber y el indisciplinamiento de las ciencias sociales, todavía se sigue pensando que se trata "de una visión distinta, que indaga las posibilidades de descolonizar la producción de conocimiento, de encontrar la manera cómo el episteme moderno, puede ser enriquecido por los conocimientos subalternizados" (Walsh; Schiwy y Castro-Gómez: 2002). Nos preguntamos, ¿se podrá dar una real descolonización del saber, si sólo aspiramos a enriquecer el episteme moderno, o al contrario, no será necesario una desestructuración radical del mismo?; ¿no se reproduce así otra forma de colonialidad del saber, pues así como el trabajo, el sudor y la sangre de los pueblos subalternizados enriquecieron los imperios, también sus conocimientos, deben enriquecer los epistemes del reino de la academia?

Si bien es positivo que se plantee: "poner en diálogo los conocimientos occidentales con las discusiones y proyectos de intelectuales indígenas" (Ibíd., 2002), y negros, esos diálogos sólo han servido como material para los textos monofónicos de prestigiosos intelectuales, innegablemente comprometidos con la descolonización del saber, pero, aún no se hace visible en dichos textos la voz, el pensamiento, los conocimientos subalternizados que se dice descolonizar.

Sigue siendo un límite que en el espacio académico, en donde se plantea reconocer a las 'epistemologías otras', sólo se estudie textos de la 'inteligencia' occidental o de académicos comprometidos con el proceso de descolo- 
nización epistémica; pero las 'epistemologías otras' siguen aún esperando, no sólo su reconocimiento discursivo, sino que se reconozca su potencial como fuente de conocimiento también para el saber académico; por ello creemos que ya es hora de que sean incorporadas como material de estudio, para que también podamos aprender de la sabiduría del viejo Antonio, de taita Marcos, de José Gualinga, de Joselino Ante, de Mama Tránsito Amaguaña, de Mama Dolores Cacuango, de Condori Mamani, de Mama Santos, de don Juan Matus, de Juan García, de Karay Miry Poty, y de muchas mujeres y hombres sabios más, para que esas sabidurías dialoguen en equidad de condiciones con Foucault, Bourdieu, Deleuze, etcétera, y sobre todo, con quienes están aportando al proceso (de)colonial del saber.

Vale no olvidar, que el reconocimiento de las 'epistemologías otras', no ha sido el resultado de un proceso de reflexión al interior de la academia o de los intelectuales críticos; sino una consecuencia de la lucha por la existencia de los pueblos sometidos a la colonialidad, construidos como 'objetos de estudio' de las ciencias sociales, y que hoy transformados en sujetos políticos e históricos; le han impuesto a la academia y a la sociedad el reconocimiento de sus saberes y de su existencia; sin embargo, esas luchas por la vida no se han hecho de la mano de la epistemología, sino desde lo que desde su propia palabra esos pueblos llaman 'sabiduría'; por ello más que hablar de 'epistemologías otras', nosotros preferimos hablar de sabidurías insurgentes.

Hablar desde las sabidurías insurgentes no significa una oposición y negación esencialista de occidente o del conocimiento que este ha producido, ni la renuncia al uso de sus categorías, puesto que esto sería absurdo. No es una invitación a prender una nueva hoguera para que- 
mar textos de epistemología o profesores; lo que se trata es de desenmascarar su perversa articulación con el poder, combatir y de-colonizar aquellas categorías que siguen siendo útiles para su ejercicio; se trata de advertir sobre la imposibilidad de de-colonizar el poder, el saber y peor el ser, si aún seguimos siendo custodios de la razón y seguimos sin ver el potencial ético, estético y político de la afectividad y las emociones en la producción de conocimientos; no es posible transformar radicalmente el actual modelo epistémico logocéntrico hegemónico, si seguimos planteando una crítica desde las mismas categorías, paradigmas, instrumental teórico y metodológico, y desde la misma perspectiva logocéntrica que decimos impugnar.

Se trata de empezar a Corazonar las epistemologías construidas por la academia, para nutrirlas de afectividad, para ponerlas a dialogar y a aprender de formas otras de conocer, de pensar y, sobre todo, de sentir, de decir y vivir la vida, ponerlas a dialogar con las sabidurías insurgentes o sabidurías del corazón e incorporar también al lenguaje académico lo que éstas pueden enseñarnos; eso ayudará a que las teorías y metodologías salgan de la frialdad de sus fortalezas, a fin de que las epistemologías reflejen la poética de la existencia, de la que están tan llenas las sabidurías. Se trata en definitiva, de la construcción de una ética y estética de la ciencia 'otra', diferente, lo que muy difícilmente será posible, desde las epistemologías de occidente dado el carácter colonial del conocimiento; sino desde el carácter insurgente de las sabidurías, que nos ofrecen referentes profundos de sentido, para que podamos sentipensar qué horizontes civilizatorios y de existencia otros son posibles.

Imaginar un horizonte de sentido 'otro' de la existencia, implica por tanto, una radical interpelación de lo que hacemos, (Lander) ${ }^{6}$ en términos éticos y políticos, 
pues nos lleva a cuestionar la forma cómo se ha estado produciendo el conocimiento, dada la complicidad que los saberes, las ciencias sociales, las humanidades y dentro de ellas las epistemologías, han tenido con el ejercicio de formas de colonialidad del saber y del ser, y que actualmente siguen cumpliendo para hacer funcional la matriz imperial/neocolonial de poder. Se trata de entender que no es posible senti-pensar la posibilidad de la vida presente y futura dentro de los universos conceptuales, epistemológicos o del conocimiento hegemónico instrumental de la ciencia tal como ha sido concebida, pues este conocimiento ya no nos salva, ya no nos ofrece posibilidades de sentido frente a la existencia, sino que por el contrario ha instrumentalizado la totalidad de la vida para que sea útil al capital y al mercado.

Una evidencia de que la ciencia no nos ofrece referentes de sentido para el vivir, la podemos encontrar en la sabiduría de este hermoso relato:

\section{El científico y el barquero}

En un hermoso lago que separaba dos pueblos vecinos, un humilde barquero, había trabajado toda su vida transportando gente de una a otra orilla.

Cierto día, cansado de tantas disquisiciones teóricas, un científico fue al lago para dar un paseo y descansar un poco, se acercó donde el barquero y le pidió que le transportase al otro lado.

-Dime barquero -le dijo el científico todo arrogante, mientras estaban navegando- ¿conoces tú algo de los misterios del universo, has estudiado acaso Astronomía, has oído del Big Bang, sabes de qué están hechas las estrellas, los planetas y las constelaciones, cuál es el orden del cosmos y cuáles son las leyes que mueven el 
universo?

-No señor, que también será eso, yo sólo conozco el lenguaje del agua -respondió el barquero con humildad.

-Que pena porque has perdido un cuarto de tu vida -dijo el científico despectivamente-.

-Y dime, ¿sabes algo de los misterios de la vida, has estudiado Biología, Anatomía?, ¿qué sabes del genoma humano?, ¿sabes cuáles son los secretos de la existencia, conoces algo de genética? -siguió preguntándole el científico.

-No señor, yo sólo conozco el lenguaje de las plantas -le respondió con tranquilidad el barquero.

-Que pena porque has perdido la mitad de tu vida -le respondió el científico.

-Podrías decirme si conoces algo de las nuevas tecnologías virtuales, de las problemáticas sociales, de las cuestiones filosóficas, económicas, políticas y culturales que ahora se dan en un mundo globalizado, has estudiado Filosofía, Antropología, Economía, Sociología, Comunicación? -Preguntó nuevamente en forma arrogante el científico.

-No señor, yo sólo conozco el lenguaje de los animales -respondió con humildad el barquero.

-Que terrible, qué es lo que has hecho todo este tiempo que has estado tan alejado de la ciencia, no te das cuenta que has perdido tres cuartos de tu vida -respondió riendo sarcásticamente el científico.

De pronto, cuando estaban en la mitad del lago, una inesperada tormenta se desata con furia, y las aguas del lago comienzan a agitarse violentamente, y ya cuando estaban a punto de naufragar, con profunda humildad 
el barquero le pregunta al científico

- ¿Disculpe señor científico, usted sabe nadar?

-No -responde aterrorizado el científico.

-Que pena-le responde el barquero- porque va a perder la totalidad de su vida.

Así sucede muchas veces con lo que aprendemos, se nos ofrece únicamente un montón de información que no es importante en los momentos más decisivos de la vida, que no nos ayuda a nadar como el barquero, sino a ahogarnos, como le sucedió al científico a pesar de todo su arrogante conocimiento, porque este se ha convertido en un arma de poder, pero que no nos ha hecho ni mejores seres humanos, ni tampoco más felices.

Para poder construir un verdadero sentido de la existencia, el conocimiento teórico, epistémico no basta, puesto que este sólo nos ofrecerá un sin fin de información, que en los momentos más importantes o más trágicos y críticos de nuestra existencia, no sirven de mucho, ¿de qué sirve tanta teoría cuando somos desgraciados o enfrentamos el dolor de la soledad o la carencia de amor?, ¿o cuando enfrentamos el terrible misterio de la muerte, qué teoría, qué epistemología nos alivia el sufrimiento cuando los seres a quienes amamos se van a caminar por las estrellas? ¿Cuando la tristeza se instala en el corazón, y el dolor del amor, el peso de la soledad no nos deja alzar el vuelo?, de poco sirve todo el acumulado teórico, de poco las metodologías y las tecnologías virtuales, nada nos dice ahí Descartes, Hegel, Habermas o Lacan. Lo que en realidad puede ayudarnos a dar luz a nuestro corazón para tal vez encontrar el camino o una simple respuesta, son historias sencillas como las de la sabiduría del barquero, pues ellas encierran no la arrogancia de la infor- 
mación y de un conocimiento frío y prepotente, sino la profundidad y la luz de una ancestral sabiduría que siempre ha estado iluminado los caminos, los sueños y el corazón de la humanidad a través del transitar del tiempo y que ha sido construida desde sus propios territorios de vivir.

Si algo no enseña esta historia, es que debemos tratar de avanzar hacia los senderos de la sabiduría, y no tan sólo de la mera acumulación de información, de datos. Creemos que ya es hora de que las universidades, las escuelas y todo el sistema educativo en general empiecen a matricular la sabiduría y la ternura en sus aulas, y entendamos que no la vamos a encontrar en los textos teóricos o metodológicos, ni en los manuales sobre ciencia, técnica, administración o marketing, pues la sabiduría no está en los libros, sino en la propia vida, ese es el libro que nunca el sistema educativo nos enseñó a leer, y es urgente que lo hagamos; es hora de que la Escuela, la Academia ofrezcan un saber para la vida, no sólo para el 'hacer' y el 'tener', sino, fundamentalmente, para el 'Ser'. Lo que debe el sistema educativo aportar al ser humano, no es simplemente una profesión para ganarnos la vida, sino ofrecernos un horizonte de sentido para aprender a vivirla; ahora más que nunca es imprescindible una educación que nos ayude a entender que la verdadera sabiduría no está encerrada en las aulas ni en los textos, sino que está hablándonos desde la vida misma.

Por lo tanto, se hace necesario Corazonar no sólo la Academia sino sobre todo la vida; para ello, es imprescindible derrumbar las fortalezas de la razón y de la ciencia, para construir formas otras de saber, un conocimiento, una sabiduría del corazón que permitan la reapropiación y reconstrucción del mundo y tenga la vida y la felicidad como horizontes; resulta imposible creer que pueda surgir una alternativa para combatir la coloniali- 
dad del poder, del saber y del ser, desde esas mismas epistemologías que han sido su fundamento. No podemos olvidar, que lo que ahora está en juego, no es sólo la reconstrucción de la academia, sino de la propia vida; no es como dice Mignolo ${ }^{7}$, la madre de todas las batallas, es la batalla epistémica, sino la batalla por la construcción de un horizonte de sentido, civilizatorio y de existencia diferente, otro, el mismo que para materializarse, más que de epistemología requiere de sabiduría.

\section{Sabidurías insurgentes y epistemología}

La diferencia entre sabiduría y epistemología, está no sólo en el tipo de saber y conocimiento que construyen, sino en el horizonte de existencia que éstos hacen posibles; mientras la epistemología aportó a una civilización que prioriza el capital sobre la vida; dichas sabidurías tienen un profundo potencial no sólo como productoras de conocimientos, sino sobre todo como fuentes de sentido de y para la existencia y ahí radica su potencial insurgente. El saber científico, el logos, la epistemología, le ha proporcionado al ser humano un cúmulo de conocimientos, de información, pero le ha ido también vaciando de sentido, esa pretensión de poder que le lleva a la apropiación de la totalidad de la vida, de la naturaleza, del ser humano, para buscar objetivarlos, codificarlos, controlarlos, dominarlos desde categorías conceptuales, desde los epistemes; ha construido el conocimiento como un otro cargado de externalidad al sujeto y a la propia vida; así, la naturaleza, el sujeto y la vida son pensados por un conocimiento que no siente ni piensa el ser, y que lo deja vaciado de sentido; un conocimiento así ha sido siempre útil para el ejercicio del poder y la dominación pues ha construido sujetos sujetados a los discursos de verdad de los conceptos. 
La sabiduría en cambio, ofrece referentes de sentido para vivir y transformar la existencia, para ser junto con los otros, por eso las llamamos sabidurías insurgentes; pues la sabiduría como enseña el viejo Antonio, "no consiste en conocer el mundo, sino en intuir los caminos que habrá de andar para ser mejor... La sabiduría consiste en el arte de descubrir por detrás del dolor, la esperanza" (Viejo Antonio, 2000).

La epistemología por teorizar alejada de la vida y hablar sólo sobre ella, no ha tenido el poder para transformar la existencia individual o colectiva, mientras que la sabiduría por estar ligada al sentido de la existencia, y haber sido construida y hablar desde la vida, lo ha estado haciendo cotidianamente. La sabiduría permite el encuentro, entre la explicación, la descripción, la interiorización, la comprensión, el diálogo entre conocimiento y amor, entre el saber y la intuición, entre el corazón y la razón, para la transformación y liberación de uno mismo y de la realidad; la sabiduría hace posible que podamos Corazonar la vida no sólo para comprenderla, sino para transformarla, de ahí su sentido insurgente.

Mientras el teórico habla desde la fría arrogancia de las teorías, los datos y la razón; el sabio lo hace desde la sencillez y el calor del corazón; mientras el epistemólogo nos dejan con la cabeza hirviendo y el corazón frío y vacío, pues hablan de las cosas más sencillas de la forma más complicada que poco ayudan al vivir; el sabio nos deja con la cabeza fresca y con el corazón lleno, pues hablan de lo más complejo del modo más sencillo y nos dejan profundas enseñanzas que transforman nuestra vida; por eso el conocimiento del experto es tan distante, incomprensible y muy poco ha ayudado para hacernos mejores y más felices. En cambio los amautas, los sabios, han explicado la profundidad de los misterios de la existencia, desde la riqueza de la metáfora, la poesía, los cuen- 
tos y relatos y sus enseñanzas han sido comprendidas y se han vuelto horizontes de sentido para orientar la vida. Al respecto la sabiduría Amaútica de Taita $\operatorname{Marcos}^{8}$ nos enseña que: "la sencillez es el camino de la inteligencia, y la humildad el sendero de la sabiduría", caminos de los cuales anda tan distanciada la academia.

Dichas sabidurías tienen un potencial no sólo epistémico, sino sobre todo ético, estético y político, por eso hablamos de ellas como sabidurías insurgentes. La sabiduría es distinta de la epistemología, pues frente al carácter totalitario de los epistemes científicos occidentales; la sabiduría ofrece un sentido totalizador, holístico, del conocimiento, que no separa el corazón de la razón, así como de la acción; frente a la voluntad colonizadora, al carácter globalizante, uni-versalista homogeneizante de los epistemes; las sabidurías insurgentes tienen un sentido contra hegemónico, pues anteponen la pluridiversalidad, el potencial político de lo heterogéneo, la respuesta insurgente de la diversidad y la diferencia y hacen posible la insurgencia de la alteridad, se abren a los otros y potencializa un diálogo de seres, sensibilidades, saberes, decires, haceres, experiencias de vida, que construyen puentes de comunicación intercultural, pero fuera de toda forma de colonialidad, de explotación, de dominación, de subordinación y exclusión.

Mientras las epistemologías siguen reproduciendo dicotomías sustentadas en el dualismo cartesiano, que separa razón/sujeto/cuerpo, desde las sabidurías insurgentes, no es posible un conocimiento que no hable desde el cuerpo, sino que se instala en el cuerpo y desde el cuerpo habla, no se trata de un conocimiento des-corporizado, desapasionado que sólo piensa y reflexiona, sino que es un saber in-corporado, que habla desde el cuerpo, y que, sobre todo, está cargado de sensibilidades, que siente, que piensa, que vive, $\mathrm{y}$ abre espacios para que podamos 
Corazonar, no sólo las epistemologías, sino la vida.

El conocimiento epistémico, logocéntrico dominante, se sustenta en la hegemonía de los sentidos externo perceptores, la vista y el oído, eso implicó la subalternización y negación de los otros sentidos como posibilidades para el conocimiento académico científico lo que condujo a su progresivo deterioro. Desde las sabidurías se nos enseña en cambio, que si queremos transitar por el mundo del sentido, y comprender el sentido del mundo y la vida, sólo lo podremos hacer desde la totalidad de los sentidos; eso nos permitirá empezar a aprender de la sabiduría de los sabores, de los olores, mirar como ellos construyen nuestra subjetividad y disparan la memoria, y son parte vital de la construcción social del recuerdo y el olvido; es necesario aprender de las sabidurías sonoras, de las sabiduría de los colores, si queremos dar luz y color a la memoria, de la sabidurías táctiles que hacen posible el encuentro y la caricia para construir formas otras de alteridad; de ahí que hacer de la totalidad de los sentidos, posibilidades para la construcción no sólo de conocimientos académicos, sino de una sabiduría para el vivir, sentipensamos que sólo será posible, no tanto desde la epistemología, sino cuando podamos Corazonar desde las sabidurías insurgentes el sentido de las epistemología dominantes, para construir sentidos otros de la existencia.

Mientras las epistemologías hegemónicas se sustentan en un saber que consideran moderno y sujeto al imperio de la moda; para las sabidurías insurgentes, el saber se sustenta en el poder de una raíz de ancestralidad que no se queda anclada en el pasado, sino que muestra su contemporaneidad, la tradición es una fuerza que viniendo de atrás del tiempo, se revitaliza permanentemente y construye memoria y que nos permite mirar el pasado, caminar el presente y soñar el porvenir. La memoria no es un depósito de cosas que vienen del pasado, sino que es 
una construcción que hace referencia a todo el acumulado social de la existencia de un pueblo; por eso la permanente necesidad política entre los pueblos indios y negros de aprender de las arrugas de los abuelos, y escuchar las voces de la sabiduría de los ancestros; pues como nos enseña el Viejo Antonio: la memoria, es la raíz de la sabiduría.

Mientras las epistemologías tienen la arrogancia de la uni-versalidad y de la posesión de la verdad, desde las sabidurías insurgentes es posible construir una pedagógica del error, que empiece también a aprender a partir de nuestras equivocaciones. El conocimiento es una respuesta a territorialidades concretas a espacios locales, a lugares desde donde se teje cotidianamente la vida, sin que por ello, se trate de culturas que buscan el aislamiento y el encerramiento en sí mismas, sino que son conscientes de que estamos viviendo en un mundo atravesado por la globalización, pero que nuestra posibilidad de enfrentarla, es sólo afirmando un rostro propio de identidad, desde nuestros propios recursos y potenciales culturales.

Los epistemes han contribuido a la construcción de una alteridad humanista, antropo-céntrica propia de la racionalidad de occidente que al hacer del hombre el centro del universo le ha permitido justificar su acción ecocida frente a la naturaleza; mientras que las sabidurías insurgentes o del corazón, plantean la necesidad de tejer una alteridad bio-céntrica, una alteridad cósmica que ponga en el centro la vida y reconstruya el tejido de la existencia, en interrelación y diálogo con todos los seres que habitan este infinito cosmos.

Las sabidurías insurgentes recuperan además junto con la afectividad, una dimensión que la razón hegemónica no lo ha hecho, la dimensión espiritual de la 
existencia, pero vista desde dimensiones políticas, como nos lo está enseñando el pueblo Kitu Kara y su llamado para 'Corazonar la vida' como forma otra de lucha espiritual y política; en el mismo sentido en que nos lo enseña la sabiduría de las naciones iroquezas: "La espiritualidad es la forma más elevada de la conciencia política”.

Por todo esto las llamamos sabidurías insurgentes, pues mientras que la epistemología le ha proporcionado a occidente el instrumental teórico y metodológico, un conocimiento útil para el ejercicio de la colonialidad; las sabidurías insurgentes o sabidurías del corazón, aportan a la de-colonización del poder, del saber y del ser, a la de-colonización de la vida, y a la construcción de sentidos otros de civilización y de existencia.

\section{Corazonamientos finales}

Tenemos el desafío de sentipensar los legados coloniales en la producción académica, que si bien a nivel de reflexión ha logrado mucho, aún falta hacerlo a nivel de la existencia, no separando como lo hizo el poder, la teoría de la vida, sino hablando a partir de ella. ¿Será posible nombrar, interpretar la realidad, pero sobre todo vivir la realidad, fuera de las cadenas epistemológicas? La humanidad muestra que a lo largo de toda su historia ha tejido la vida sin epistemología, sino de la mano de la sabiduría.

Si la colonialidad nos llevó a perder nuestro propio camino, y el camino para el encuentro con los otros; hoy más que nunca como dice el anciano sabio Guaraní Kari Miri Poty ${ }^{9}$, es urgente que aprendamos a ...reencausar nuestro camino y nuestro caminar... a ser puentes para una nueva existencia...; esto implica empezar a construir senderos de descolonización, que permitan 
enfrentar toda forma de colonialidad del poder, del saber y del ser; pues sólo así podremos como nos dice el sabio Guaraní ...reencontrarnos con nosotros mismos y con los otros y en consecuencia, reencontrar nuestro ... ser, estar y sentir en el mundo...

La de-colonización del saber implica, como nos señala el anciano sabio, que debemos aprender a crear, a ser nuestra propia agua, nuestro propio sol, nuestra propia tierra; lo que significa, empezar a hacer escuchar nuestras propias voces, a hablar desde nuestros propios territorios del vivir, desde nuestros propios lugares y territorialidades, construir políticas del nombrar, del decir distintas, a fin de romper con un saber ventrílocuo que repite y no habla desde y con su propia voz, implica dejar de ser reflejo para ser presencia vital.

Quizás este sea el momento de empezar a tejer una gran red de Sabidurías y Ciencias Sociales de AbyaYala, que se proponga tejer, desde la riqueza de la diversidad y la diferencia, que sea un espacio para que todas las propuestas de los diversos actores sociales, políticos e históricos que tienen la vida como horizonte, puedan ser escuchadas, debatidas, enriquecidas; ya sea aquellas que vienen desde los marcos epistemológicos y que buscan sentipensando por sí mismos, combatir la colonialidad epistémica que enfrentamos, y puedan abrir espacios de encuentro no sólo trans, inter, sino sobre todo anti-disciplinarios, a fin de que puedan entrar en diálogo con aquellas sabidurías insurgentes que desde la cotidianidad, buscan tejer horizontes otros de existencia.

La de-colonización del saber, del ser, de la afectividad, de los imaginarios, las subjetividades y los cuerpos implica no únicamente la impugnación radical de los saberes, de las epistemologías hegemónicas, sino sobre todo requiere, como dice la sabiduría de Karai Miri: 
"mantener siempre encendido el fuego del corazón, para que reviva el espíritu de la palabra, pues sólo así podremos reencontrarnos con los demás, con los otros, pero sobre todo, podremos reencontrarnos con nosotros mismos..."; de ahí la necesidad de empezar a Corazonar no sólo las epistemologías, sino sobre todo la propia vida.

Debemos matricular la ternura, la afectividad en la Academia, debemos empezar a aprender con mayor humildad lo que las sabidurías del corazón pueden enseñarnos; asunto que no se trata sólo de una cuestión académica, sino, que es una cuestión esencialmente espiritual, ética y política, pues lo que está en juego no es sólo la transformación radical de la actual estructura en la producción de un conocimiento instrumental al poder, sino sobre todo, la transformación de las situaciones de existencia de las sociedades subalternizadas por la colonialidad, marcadas por la marginalización, la exclusión y la dominación, en la que viven la mayor parte de la población del planeta (Lander) ${ }^{10}$; lo que está en el centro de todo esto, es la lucha por la construcción de horizontes de sentido civilizatorios y de existencia otros, que tengan la felicidad como horizonte, que permitan Corazonar la vida y hagan posible la insurgencia de formas otras de sentir, de pensar, de imaginar, de decir, de nombrar, de hacer, de significar, para construir una distinta ética, estética y erótica de la existencia, que para que sea realidad, requiere no sólo de epistemología, sino sobre todo de ternura y sabiduría.

Y si bien el camino de la de-colonización es un proceso largo, difícil, nos alienta las palabras del viejo Antonio que nos advierte que es largo el camino de los sueños, para que a pesar de los anuncios de fin de la historia y el aparente triunfo absolutista de la globalización del mercado, continuemos militando intransigentemente por los sueños y la vida, con la actitud del loco arquero de la luna. 
Un joven arquero tenía el sueño de un día llegar a cazar la Luna. Desde entonces, cada noche salía a disparar sin descanso sus flechas hacia el hermoso astro que sonriente lo miraba y le iluminaba con su luz de plata.

La gente de la aldea que veía al arquero disparar a la Luna, pensó que estaba loco, y comenzaron todos a burlarse de él y a llamarle 'el loco arquero de la luna', y a hacer todo tipo de comentarios irónicos y crueles.

Sin embargo, el joven arquero, -sin importarle lo que podían pensar de él los demás-, seguía inmutable en su objetivo y continuaba noche tras noche, disparando sus flechas a la Luna.

Pasó el tiempo, y el arquero se hizo viejo, y si bien, el loco arquero de la luna, nunca llegó a cazar la luna, si se convirtió en el mejor arquero que alguien puede haber conocido en todo lugar y tiempo.

Pues lo que importa no es si alcanzamos o no la luna, sino lo que vayamos construyendo en el largo camino de la lucha por los sueños. La única diferencia es quizás, que nos anima la terca e intransigente esperanza, de que si podemos alcanzar la luna.

Finalmente, la pregunta sobre ¿cómo podemos cuestionar el modelo logocéntrico, si seguimos haciéndolo desde la misma perspectiva logocéntrica que decimos impugnar?, sentipensamos que debe ser un horizonte que nos lleve a la urgente necesidad de hacer un radical cuestionamiento y ruptura con nuestras actuales prácticas, no sólo académicas sino de vida. La sabiduría Chasídica nos enseña que "el mayor conflicto que enfrenta la humanidad, las sociedades y los individuos es un conflicto entre el pensamiento, la palabra y la acción, pues somos incapaces de decir lo que pensamos, y peor aún de hacer lo que decimos", deberíamos incluir también lo que sentimos; de ahí 
la necesidad de llenar las teorías y las palabras de vida y empezar a construir una academia que tenga la existencia como horizonte, una academia comprometida con la vida.

Por ello, cómo explicar lo del Corazonar no tanto a las y los académicas, sino a mi pequeño hijo, a las niñas y niños, a las y los jóvenes que están soñando y luchando por muchos mundos posibles y de otro modo, por horizontes diferentes de civilización y de existencia; cómo hablarles del potencial de las sabidurías insurgentes y de las profundas lecciones de vida que estas nos ofrecen; nuevamente se evidencia que resulta insuficiente hacerlo desde la epistemología, por ello he querido hacerlo, desde la poética de la misma sabiduría; ojalá esta sea una forma de responder a esa tenaz interrogante y de evidenciar que es necesario, urgente y posible, Corazonar desde las sabidurías insurgentes, no sólo la academia, las epistemologías, sino sobre todo la propia vida.

\section{Corazonando para mi hijo}

Hijo mío:

Tanto tiempo sin mirar la vida, sin escuchar lo que nos busca enseñar, ciegos a la sabiduría que nuestra arrogancia no permite hallar.

Tanto tiempo sólo viendo y oyendo, lo que nos impone la tirana razón, ya es hora de volar a la vida y abrir las puertas del corazón.

La sabiduría no está en la razón, al corazón hay que dejar hablar, ya es tiempo de empezar hijo mío, desde la ternura a CORAZONAR.

Que profunda es la sabiduría, que está escrita en el libro de la vida, ya es hora de empezar a leerlo, con pasión, ternura y alegría.

Muy poco te ayudan las teorías, para que en la vida en verdad te realices, la ciencia no nos ha hecho mejores, ni ha podido hacernos más felices.

Aprende pues,

a mirar lo que la vida enseña,

escucha ya,

la sabiduría que en ella se encierra.

Aprende lo que te dice la luna, va creciendo hasta ser luna llena, 
su sendero de luz nos enseña, que no hay sombras, ni noches eternas. Aprende de las mariposas, el milagro de la transformación, descubre que hasta una fea crisálida, guarda colores en el corazón.

Aprende de la vía del agua, es profundo lo que nos quiere enseñar, nace de una gota de luna, y sabe que su destino es ser mar. Nada tan frágil ni tan poderoso, como su cristalina belleza, su fluir al océano te enseña, que nuestro destino es también la grandeza.

La sabiduría del árbol te enseña, que para soportar cualquier vendaval debemos tener fuertes las raíces, igual es hijo mío con nuestra identidad. La montaña te enseña en silencio, que para alcanzar las cumbres de la vida, debes luchar con esfuerzo, con coraje, pasión y alegría.

Si quieres ser libre véncete a ti mismo, no te quedes parado al filo de la vida, corre riesgos busca lo imposible, que la vida está para ser vivida.

Procura de todo y de todos, con profunda humildad aprender, pues si hasta la hierba crece, como podemos negarnos a crecer Todo cambio empieza en uno mismo, cambia entonces tu vida primero, pues no puedes ser luz de los otros, si no hay luz en tu propio sendero.

Aprende pues...

Mira el mundo con ojos de mago, cabalga en las alas de la fantasía, ábrete al azar a lo imprevisible, no pierdas tu capacidad de asombro ante el bello milagro de la vida Mantén encendido el fuego de la magia de los sueños, milita por la ternura y la alegría,

haz parir estrellas bailadoras, sé cazador de nuevas auroras.

No dejes que te impongan tu vida, lucha siempre por ser tu propio dueño, no hipoteques en nombre del poder, el poder constructor de tus sueños.

Nunca olvides que la ternura, la esperanza, el amor, la alegría, son fuerzas insurgentes, para cambiar la historia y la vida.

Si hay problemas no te encierres en ti mismo, pues nuestra fuerza no está solo en nosotros, pide ayuda descubre que el poder, está en el amor que das y recibes de los otros. Si alguien necesita de ti sé generoso, ofrécele tu corazón, dale tus manos, No olvides que el mayor reto que tienes hijo mío, es construirte como un digno ser humano.

Aprende pues...

Sólo raíces y alas, a tus hijos procura heredar, 
raíces para que sepan quienes son y alas para que puedan volar.

Ábreles el corazón que les conmueva el dolor, la injusticia, las cosas bellas, ayúdales a andar por la tierra y a volar también por las estrellas.

Que el poder de los cuatro elementos, que tejieron la trama de la vida, vivan siempre en tu corazón y te den luz, fuerza y alegría.

Cristalino se como el agua, pon en todo la pasión del fuego, generoso se como la tierra, vuela siempre libre como el viento.

Aprende pues,

a mirar lo que la vida enseña,

escucha ya,

la sabiduría que en ella se encierra.

\section{Notas}

1 Uni-versal hace referencia al sentido monocultural, a una sola forma (uni) de mirar, entender y explicar el mundo y la vida impuesta por occidente a nivel planetario (universal). El universalismo es una construcción del poder para legitimar la superioridad de los dominadores e imponer sus visiones de la realidad como discursos de verdad. Una de las instituciones que se crea sobre la base del uni-versalismo, es la "universidad", que se encarga de la reproducción y legitimación de esos discursos

2 Ecocidio, hace referencia al asesinato de la naturaleza.

3 Cit en LE BRETON, David. Las pasiones ordinarias: Antropología de las emociones. Ediciones Nueva Visión, Buenos Aires, 1998

4 CASTILlEJO, Alejandro. Poética de lo otro: Antropología de la guerra, la soledad y el exilio interno en Colombia. Instituto Colombiano de Antropología e Historia / COLCIENCIAS, Bogotá, 2000.

5 El Viejo Antonio, líder indígena chiapaneco, guía espiritual y político del movimiento Zapatista de Liberación Nacional, maestro del sub comandante Marcos

6 LANDER, Edgardo. ¿Conocimiento para qué?. ¿Conocimiento para quien?. Reflexiones sobre la universidad y la geopolitica de los saberes hegemónicos. En: Material seminario Conocimiento y globalización neoliberal, Doctorado en Estudios Culturales Latinoamericanos, Universidad Andina Simón Bolívar, Quito, 2005.

7 Frase pronunciada por Walter Mignolo, en la 14 conferencia internacional "Desarrollo e interculturalidad, imaginario y diferencia: la nación en el mundo andino, convocado por la Academia de la Latinidad, celebrado en la Universidad Andina Simón Bolívar, en 
Quito del 21 al 23 de septiembre de 2006.

8 Taita Marcos, Yachag, hombre sabio, guía espiritual del pueblo Kayanbi

9 Karai Miri Poty, guía espiritual y político del pueblo Guaraní. Cit en: GUERRERO ARIAS, Patricio. Corazonar una antropología comprometida con la vida. Nuevas miradas para la descolonización del poder, del saber y del ser. FONDEC, Asunción-Paraguay, 2007

10 LANDER, Edgardo. Op. Cit.

\title{
Bibliografía
}

\author{
ALBÁN, Adolfo \\ 2006 “Conocimiento y lugar: más allá de la razón hay un mundo \\ de colores”. En Tejiendo textos y saberes: Cinco hilos para \\ pensar los estudios culturales, la colonialidad y la intercultu- \\ ralidad, ALBAN Adolfo (Compilador), Popayán: Editorial \\ Universidad del Cauca, \\ CASTILLEJO, Alejandro \\ 2000 Poética de lo otro: Antropología de la guerra, la soledad y el \\ exilio interno en Colombia. Instituto Colombiano de \\ Antropología e Historia / COLCIENCIAS, Bogotá. \\ CASTRO-GÓMEZ, Santiago \\ 2005 La Hybris del punto cero: Biopoliticas imperiales y coloniali- \\ dad del poder en la Nueva Granada (1750-1810), en mate- \\ rial de estudio Seminario Epistemología y Estudios \\ Culturales, Universidad Andina Simón Bolívar, Quito. \\ DUSSEL, Enrique \\ 1994 El encubrimiento del otro: hacia el origen del mito de la \\ modernidad. Quito: Editorial Abya-Yala. \\ GARCÉS, Fernando \\ 2005 Las políticas del conocimiento y la colonialidad lingüística y \\ epistémica. En: Pensamiento crítico y matriz (de)colonial: \\ Reflexiones Latinoamericanas. WALSH, Catherine (edito- \\ ra). Universidad Andina Simón Bolívar / Quito: Abya-Yala. \\ GUERRERO, Patricio \\ 2007 CORAZONAR una antropología comprometida con la vida: \\ Nuevas miradas desde Abya-Yala para la descolonización del \\ poder, del saber y del ser. FONDEC, Asunción-Paraguay. \\ 2002 La Cultura: Estrategias conceptuales para comprender la \\ identidad, la diversidad, la alteridad y la diferencia, Quito: \\ Abya-Yala.
}


1993 El saber del mundo de los cóndores: identidad e insurgencia de la cultura andina. Quito: Abya-Yala.

KOWI, Ariruma

2005 Barbarie, civilización e interculturalidad. En: Pensamiento crítico y matriz (de)colonial: Reflexiones Latinoamericanas. WALSH Catherine (editora). Universidad Andina Simón Bolívar / Quito: Abya-Yala.

KUSCH, Rodolfo

1998 Pensamiento indígena y pensamiento popular, en Obras completas tomo II, Argentina: Editorial Fundación Ross.

LANDER, Edgardo

2005(a) ¿Conocimiento para que? ¿Conocimiento para quien?. Reflexiones sobre la universidad y la geopolitica de los saberes hegemónicos. En: Material seminario: Conocimiento y globalización neoliberal. Doctorado en Estudios Culturales Latinoamericanos. Universidad Andina Simón Bolívar, Quito.

LE BRETON, David

1998 Las pasiones ordinarias: Antropología de las emociones. Buenos Aires: Ediciones Nueva Visión.

LEÓN, Catalina

2005 Hacia una posible superación de la meta historia de lo lationoamericano. En: Pensamiento crítico y matriz (de)colonial: Reflexiones latinoamericanas, WALSH, Catherine, Universidad Andina Simón Bolivar, Quito,: 115-120

MATURANA, Humberto

2004 Transformación en la convivencia. J-C-SAEZ Editor, Chile.

SÁBATO, Ernesto.

2001 La resistencia, Argentina: Seix Barral.

SEATLE, Jefe Indio.

1998 La carta del jefe indio Seatle. Acku Quinde, Sistema de Bibliotecas campesinas de Cajamarca, Perú.

VIEJO ANTONIO

2000 Desde las montañas del sureste mexicano (cuentos, leyendas $y$ otras posdatas del Sup Marcos. Recopilación y notas Alguien. México: Plaza Janes Editores S.A.

WALSH, Catherine.

2006 Interculturalidad y colonialidad del poder. Un pensamiento y posicionamiento otro desde la diferencia colonial. En: Interculturalidad, descolonización del Estado y del conocimiento, WALSH, Catherine; Mignolo, Walter; Álavaro 
García Linera, Buenos Aires: Ediciones del Signo.

2005 (Re)Pensamiento crítico y (De)Colonialidad, en: "Pensamiento crítico y matriz (de)colonial, reflexiones latinoamericanas", Universidad Andina Simón Bolívar / Quito: Ed. Abya-Yala.

WALSH, Catherine; SCHiWY, Freya y Santiago CASTRO-GOMEZ

2002 Indisciplinar las ciencias sociales. Geopolíticas del conocimiento y colonialidad del poder. Perspectivas desde lo andino. Universidad Andina Simón Bolivar / Quito: Abya-Yala. ZAPATA OLIVELLA, Manuel.

1997 La rebelión de los genes. El mestizaje americano en la sociedad futura. Bogota: Altamira Ediciones. 